Proceedings of the International Congress on Advances in Applied Physics and Materials Science, Antalya 2011

\title{
ZnO Nanorods on Nanofibrous ZnO Seed Layers by Hydrothermal Method and Their Annealing Effects
}

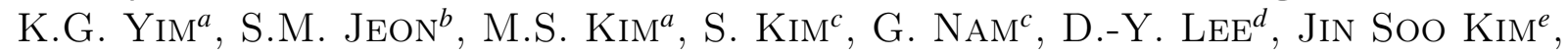
Jong SU Kim ${ }^{f}$ AND J.-Y. LEEM ${ }^{a, b, *}$

${ }^{a}$ Department of Nano Systems Engineering, Center for Nano Manufacturing, Inje University Gimhae 621-749, Republic of Korea

${ }^{b}$ SMS PE Team 5, MagnaChip Semiconductor Ltd., Gumi 730-723, Republic of Korea

${ }^{c}$ School of Nano Engineering, Inje University, Gimhae 621-749, Republic of Korea

${ }^{d}$ Epi-manufacturing Technology, Samsung LED Co. Ltd., Suwon 443-373, Republic of Korea

${ }^{e}$ Division of Advanced Materials Engineering, Chonbuk National University, Jeonju 561-756, Republic of Korea

${ }^{f}$ Department of Physics, Yeungnam University, Gyeongsan 712-749, Republic of Korea

$\mathrm{ZnO}$ nanorods were grown by using the hydrothermal method on $p$-type $\mathrm{Si}(100)$ substrates with nanofibrous $\mathrm{ZnO}$ seed layers. Before the $\mathrm{ZnO}$ nanorods growth, nanofibrous $\mathrm{ZnO}$ seed layers were spin-coated onto the Si substrates. The structural and optical properties of $\mathrm{ZnO}$ nanorods were characterized by scanning electron microscopy, X-ray diffraction, and photoluminescence. The fibrous $\mathrm{ZnO}$ nanorods is possible due to the surface morphology of the nanofibrous $\mathrm{ZnO}$ seed layers. To investigate annealing effects of the $\mathrm{ZnO}$ nanorods, the post-annealing process was carried out at various temperatures ranging from 300 to $700^{\circ} \mathrm{C}$ under argon conditions. The structural and optical properties of the $\mathrm{ZnO}$ nanorods were also affected by the post-annealing treatment.

PACS: 81.05.Dz, 81.15.Lm, 78.55.Et

\section{Introduction}

$\mathrm{ZnO}$ has attracted considerable attention, because it has a hexagonal wurzite structure with a direct wide band-gap of $3.37 \mathrm{eV}$, a large exciton binding energy of $60 \mathrm{meV}$ at room temperature. These properties of $\mathrm{ZnO}$ impose its significant potential in various applications such as in transparent electrodes and blue/UV light emitting diode (LED). Various growth techniques, such as metal-organic chemical vapor deposition (MOCVD) [1], vapor phase transport (VPT) [2], and hydrothermal method [3] have been successful in creating the $\mathrm{ZnO}$ nanowires [4], nanorods [2], and nanotubes [5]. Among these growth techniques, hydrothermal method has been studied in view of its simplicity, low growth temperature, large scale growth, flexible application, mass productivity, and the growth of one-dimensional (1D) nanostructure. Recently, 1D nanorods have attracted considerable interest due to their remarkable physical and chemical properties [6]. Several researchers have studied 1D nanorods growth on homogeneous film with various growth conditions $[7,8]$. However, there have been few reports considering $\mathrm{ZnO}$ nanorods grown on nanofibrous $\mathrm{ZnO}$ seed layers by using the hydrothermal method.

In this work, $\mathrm{ZnO}$ nanorods on nanofibrous $\mathrm{ZnO}$ seed layers were fabricated by using a hydrothermal method. For the post-annealing effects of the $\mathrm{ZnO}$ nanorods, they were post-annealed at various temperatures in Ar condi-

\footnotetext{
* corresponding author
}

tions. The structural and optical properties of the $\mathrm{ZnO}$ nanorods were investigated by using field-emission scanning electron microscopy (FE-SEM), X-ray diffraction (XRD), and photoluminescence (PL).

\section{Experimental details}

The $\mathrm{ZnO}$ nanorods were grown by using the hydrothermal method on $p$-type Si (100) substrates with nanofibrous $\mathrm{ZnO}$ seed layers. Before the growth of $\mathrm{ZnO}$ seed layers, $\mathrm{Si}$ substrates were cleaned by immersion in a piranha solution $\left(\mathrm{H}_{2} \mathrm{SO}_{4}: \mathrm{H}_{2} \mathrm{O}_{2}=8: 1\right)$ at $110^{\circ} \mathrm{C}$ for $15 \mathrm{~min}$ and then in hydrofluoric acid ( $\mathrm{HF} 50 \%$ : $\left.\mathrm{H}_{2} \mathrm{O}=1: 9\right)$ for $1 \mathrm{~min}$. Nanofibrous $\mathrm{ZnO}$ seed layers were prepared by spin-coating method. The sol solution was prepared by dissolving $0.6 \mathrm{M}$ zinc acetate dehydrate $\left[\mathrm{Zn}\left(\mathrm{CH}_{3} \mathrm{COO}\right)_{2} \cdot 2 \mathrm{H}_{2} \mathrm{O}\right]$ in $0.6 \mathrm{M}$ 2-methoxyethanol as a solvent, and monoethanolamine (MEA) was added to the stable sol solution. The molar ratio of MEA to zinc acetate dehydrate was maintained at 1.0. The resultant solution was stirred at $60^{\circ} \mathrm{C}$ for $2 \mathrm{~h}$. The sol solution was dropped onto Si substrates, which was rotated at $3000 \mathrm{rpm}$ for $20 \mathrm{~s}$. The $\mathrm{ZnO}$ seed layers were pre-heated at $300^{\circ} \mathrm{C}$ for $10 \mathrm{~min}$ and then cooled in the hot plate (slow cooling). The procedures from spin-coating to pre-heating were repeated three times. The $\mathrm{ZnO}$ seed layers were inserted into a furnace and post-heated in air at $450^{\circ} \mathrm{C}$ for $1 \mathrm{~h}$. For the synthesis of $\mathrm{ZnO}$ nanorods, zinc nitrate hexahydrate $\left[\mathrm{Zn}\left(\mathrm{NO}_{3}\right)_{2} \cdot 6 \mathrm{H}_{2} \mathrm{O}\right]$ and hexamethylenetetramine (HMT) $\left[\mathrm{C}_{6} \mathrm{H}_{12} \mathrm{~N}_{4}\right]$ were dissolved in deionized water at room temperature. The concentra- 
tions of both components were fixed at $0.3 \mathrm{M}$. The substrate was immersed in the aqueous solution. The growth temperature was kept at $140^{\circ} \mathrm{C}$ for $6 \mathrm{~h}$. The resultant substrate was rinsed with deionized water and blown dry with nitrogen gas $(99.9999 \%)$. The $\mathrm{ZnO}$ nanorods were annealed at 300,500 , and $700^{\circ} \mathrm{C}$ for 20 min under $\mathrm{Ar}$ condition by using a thermal annealing system.

\section{Results and discussion}

Figure 1 shows the SEM image of the $\mathrm{ZnO}$ seed layers. The surface of the $\mathrm{ZnO}$ seed layers with slow cooling exhibits nanofibrous structure. Zhao et al. [9] reported that the $\mathrm{ZnO}$ nanofibrous seed layer was due to the slow cooling. During slow cooling, there is enough time for ions and/or molecules to aggregate along the crystal plane having similar lattice match in order to decrease their high surface energy. This process produces the $\mathrm{ZnO}$ nanofibrous nanorods.

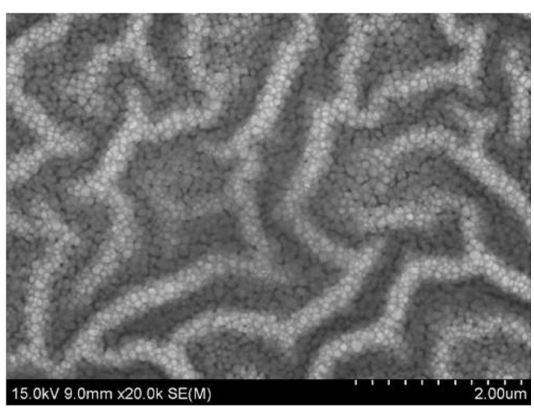

Fig. 1. SEM image of the nanofibrous $\mathrm{ZnO}$ seed layers.

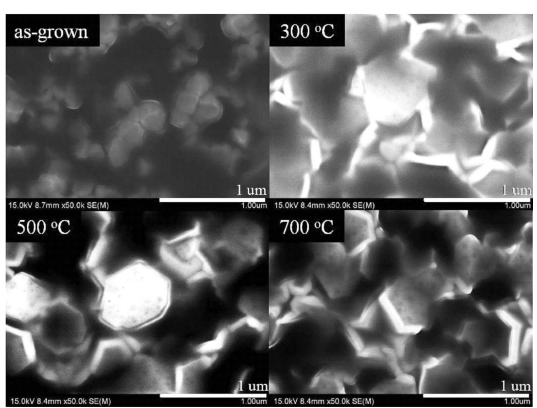

Fig. 2. SEM images of the as-grown $\mathrm{ZnO}$ nanorod and $\mathrm{ZnO}$ nanorods post-annealed at temperatures of 300 , 500 , and $700^{\circ} \mathrm{C}$.

Figure 2 shows top-view SEM images of the as-grown $\mathrm{ZnO}$ nanorods and the $\mathrm{ZnO}$ nanorods at various post-annealing temperature of 300,500 , and $700{ }^{\circ} \mathrm{C}$. The polygonal-shaped $\mathrm{ZnO}$ nanorods covered fibrously the $\mathrm{Si}$ substrates. The fibrous $\mathrm{ZnO}$ nanorods are possible due to the surface morphology of the nanofibrous $\mathrm{ZnO}$ seed layers. The formation of $\mathrm{ZnO}$ nanorods is influenced by morphology of the seed layers [10]. There are two possible reasons for the formation of the fibrous $\mathrm{ZnO}$ nanorods.
One is along the randomly distributed (002) planes of seed layers. As reported by Kim et al. [11], the rugged faceted surface is responsible for the formation of the inclined nanorods due to the preferential formation of the nanorods along the $\mathrm{ZnO}(002)$. The density and size of the grown $\mathrm{ZnO}$ nanorods depended significantly on the surface morphology and density of $\mathrm{ZnO}$ seed layers [12].

As-grown $\mathrm{ZnO}$ nanorods were post-annealed at 300 , 500 , and $700^{\circ} \mathrm{C}$ in Ar condition. After post-annealing, the nanopores of $\approx 50 \mathrm{~nm}$ are observed at the surface of $\mathrm{ZnO}$ nanorods and the diameters of the $\mathrm{ZnO}$ nanorods are increased from 200 to $500 \mathrm{~nm}$. For high annealing temperature, the nanopore size increases gradually. According to forming the nanofibrous seed layer by slow cooling, the $\mathrm{ZnO}$ nanorods were inclined.

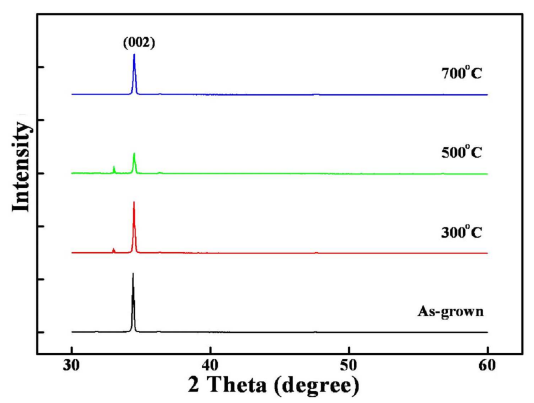

Fig. 3. XRD diffraction patterns of the as-grown $\mathrm{ZnO}$ nanorod and $\mathrm{ZnO}$ nanorods post-annealed at temperatures of 300,500 , and $700^{\circ} \mathrm{C}$.

Figure 3 shows the XRD patterns of the as-grown $\mathrm{ZnO}$ nanorods and annealed $\mathrm{ZnO}$ nanorods. For all the samples, the diffraction peaks of (002) are only observed. The (002) diffraction peak located at $34.5^{\circ}$ is the most intensive. In generally, the $\mathrm{ZnO}$ (002) peak indicate that the preferred orientation due to the lowest surface energy is along the (001) basal plane in $\mathrm{ZnO}$ [13].

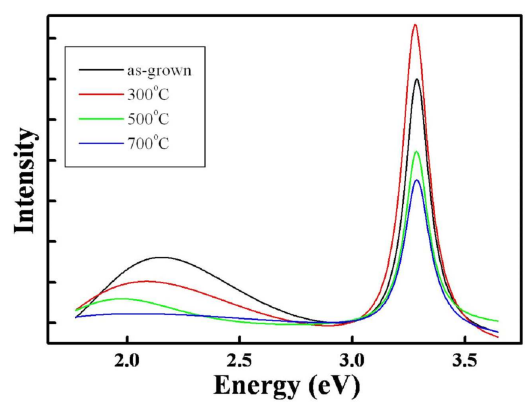

Fig. 4. PL spectra of the as-grown $\mathrm{ZnO}$ nanorod and $\mathrm{ZnO}$ nanorods post-annealed at temperatures of 300 , 500 , and $700{ }^{\circ} \mathrm{C}$.

Figure $4 \mathrm{PL}$ measurements were carried out at room temperature to examine the effect of the post-annealing on the optical properties of the $\mathrm{ZnO}$ nanorods. Figure 4 shows the PL spectra of the as-grown $\mathrm{ZnO}$ nanorods and 
the annealed $\mathrm{ZnO}$ nanorods. All of the samples exhibit two emission peaks. One is the strong UV region and the other is the weak deep-level emission (DLE) at visible region. The UV emission is the exciton recombination related near-band edge emission (NBE) and the DLE usually accompanies the presence of structural defects and impurities [14]; these can include an oxygen vacancy $\left(\mathrm{V}_{\mathrm{O}}\right)$, a zinc vacancy $\left(\mathrm{V}_{\mathrm{Zn}}\right)$, an oxygen atom at the zinc position in the crystal lattice $\left(\mathrm{O}_{\mathrm{Zn}}\right)$, a zinc atom at the oxygen position in the crystal lattice $\left(\mathrm{Zn}_{\mathrm{O}}\right)$, interstitial oxygen $\left(O_{\mathrm{i}}\right)$, and interstitial zinc $\left(\mathrm{Zn}_{\mathrm{i}}\right)$. The NBE peak position is around $3.285 \mathrm{eV}$, and the NBE peak position is hardly affected by the existence of pores at the surfaces of the $\mathrm{ZnO}$ nanorods. However, the DLE peak is shifted from green-yellow to orange region as pores are formed on the surfaces of the $\mathrm{ZnO}$ nanorods. Besides, the DLE peak is red-shifted from orange to red region with the post annealing temperature increase of the $\mathrm{ZnO}$ nanorods. The green-yellow emission (500-600 nm) and orange $(610 \mathrm{~nm})$ in $\mathrm{ZnO}$ has been attributed to intrinsic defects such as $\mathrm{Zn}_{\mathrm{i}}$ and $\mathrm{V}_{\mathrm{O}}[15]$ and interstitial defects such as $\mathrm{O}_{\mathrm{i}}[16]$. Few studies have reported red emissions in undoped $\mathrm{ZnO}$, and the origin is still under debate.

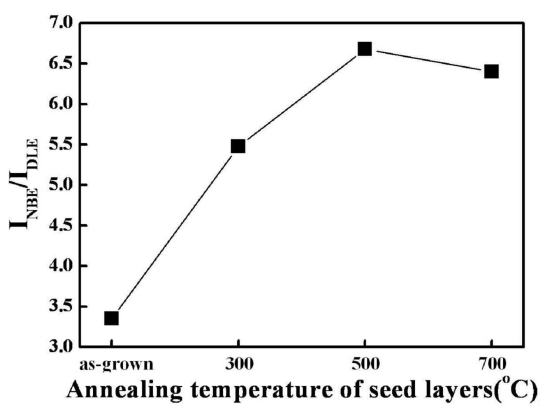

Fig. 5. PL intensity ratio of the NBE to the DLE as a function of the post-annealing temperatures.

Figure 5 shows the PL intensity ratio of the NBE to the DLE as a function of the post-annealing temperature. In general, the large intensity ratio of the NBE to the DLE indicates that the $\mathrm{ZnO}$ nanorods have better optical properties. It can be seen that intensity ratio of the NBE to the DLE increases in post-annealed $\mathrm{ZnO}$ nanorods compared to the as-grown $\mathrm{ZnO}$ nanorods. The PL intensity ratio of the samples increased from 3.35 to 6.68 as the post-annealing temperature increased. The bigger the intensity ratio, the higher the quality of the $\mathrm{ZnO}$ nanorods [17]. Improved emission efficiency has also been reported in porous GaN [18]. The improvement of the post-annealed $\mathrm{ZnO}$ nanorods is explained in terms of increase of the emission rate of excess carriers due to the porous $\mathrm{ZnO}$ nanorods.

\section{Conclusions}

The $\mathrm{ZnO}$ nanorods on nanofibrous seed layers were grown by using hydrothermal method and were post-annealed in Ar condition at temperature of 300, 500, and $700{ }^{\circ} \mathrm{C}$ for $20 \mathrm{~min}$. The formation of as-grown $\mathrm{ZnO}$ nanorods is influenced by morphology of the nanofibrous $\mathrm{ZnO}$ seed layers. After post-annealing, the nanosized pores are formed on the surfaces of $\mathrm{ZnO}$ nanorods. As the post-annealing temperature increased, the PL intensity ratio significantly increased. Post-annealing process of $\mathrm{ZnO}$ nanorods plays an important role in enhancing the optical properties.

\section{Acknowledgments}

This research was supported by Basic Science Research Program through the National Research Foundation of Korea (NRF) funded by the Ministry of Education, Science and Technology (No. 2011-0003067).

\section{References}

[1] W.I. Park, D.H. Kim, S.-W. Jung, G.-C. Yi, Appl. Phys. Lett. 80, 4232 (2002).

[2] S. Oh, M. Jung, J. Koo, Y. Cho, S. Choi, S. Yi, G. Kil, J. Chang, Physica E 42, 2285 (2010).

[3] B. Liu, H.C. Zeng, J. Am. Chem. Soc. 125, 4430 (2003).

[4] Y. Li, G.W. Meng, L.D. Zhang, Appl. Phys. Lett. 76, 2011 (2000).

[5] Y.J. Xing, Z.H. Xi, Z.Q. Xue, X.D. Zhang, J.H. Song, Appl. Phys. Lett. 83, 1689 (2003).

[6] J. Wang, M.S. Gudiksen, X. Duan, Y. Cui, C.M. Lieber, Science 293, 1455 (2001).

[7] J.-J. Wu, S.-C. Liu, J. Phys. Chem. B 106, 9546 (2002).

[8] S.-H. Park, S.-Y. Seo, S.-H. Kim, Appl. Phys. Lett. 88, 251903 (2006).

[9] J. Zhao, Z.-G. Jin, T. Li, X.-X. Liu, J. Eur. Ceram. Soc. 26, 2796 (2006).

[10] B.H. Kong, H.K. Cho, J. Cryst. Growth 289, 370 (2006).

[11] D.C. Kim, B.H. Kong, H.K. Cho, D.J. Park, J.Y. Lee, Nanotechnology 18, 015603 (2007).

[12] S.-D. Lee, Y.-S. Kim, M.-S. Yi, J.-Y. Choi, S.-W. Kim, J. Phys. Chem. C 113, 8954 (2009).

[13] M.S. Kim, K.G. Yim, M.Y. Cho, J.-Y. Leem, D.-Y. Lee, J.S. Kim, J.S. Kim, J.-S. Son, J. Korean Phys. Soc. 58, 515 (2011).

[14] S.-H. Jeong, B.-S. Kim, B.-T. Lee, Appl. Phys. Lett. 82, 2625 (2003).

[15] Y.-Y. Peng, T.-E. Hsieh, C.-H. Hsu, Nanotechnology 17, 174 (2006).

[16] S.A. Studenikin, N. Golego, M. Cocivera, J. Appl. Phys. 84, 2287 (1998).

[17] S.W. Xue, X.T. Zu, W.G. Zheng, M.Y. Chen, X. Xing, Physica B 382, 201 (2006).

[18] A.P. Vajpeyi, S. Tripathy, S.J. Chua, E.A. Fitzgerald, Physica E 28, 141 (2005). 